nephron

Practice
Nephron 2016;134:172-176

DOI: $10.1159 / 000448081$
Received: March 5, 2016

Accepted after revision: June 26, 2016

Published online: July 12, 2016

\title{
Insights into the Mechanisms of the Acute Kidney Injury-to-Chronic Kidney Disease Continuum
}

\author{
Koji Takaori Motoko Yanagita \\ Department of Nephrology, Kyoto University Graduate School of Medicine, Kyoto, Japan
}

\section{Key Words}

Acute kidney injury · Chronic kidney disease $\cdot$ Proximal tubule injury

\begin{abstract}
Acute kidney injury (AKI) is an increasingly common clinical problem with significant impact on long-term patient outcome. Recent clinical trials demonstrate that AKI is closely related to the progression of chronic kidney disease (CKD) and end-stage renal disease, though the precise mechanisms linking AKI to CKD remain unclear. While inflammation, microvascular rarefaction and hypoxia are involved in the AKI-to-CKD continuum, proximal tubule injury seems to play an important role in the progression of CKD. In this review, we focus on the mechanisms of the AKI-to-CKD continuum, especially the mechanism by which injury to the proximal tubules triggers progression to CKD. Elucidating the mechanisms involved in the AKI-to-CKD continuum will support the development of therapeutic options to prevent progression from AKI to CKD.

๑) 2016 S. Karger AG, Basel
\end{abstract}

\section{Introduction}

Acute kidney injury (AKI) is a very common disease associated with multiple organ failure, poor outcome, longer hospital stay, and higher medical cost. Accordingly, it has received a great deal of attention in recent years. In the United States, about 300,000 people die from AKI each year, and the presence of AKI increases the length of a patient's hospital stay by 3.5 days [1]. Furthermore, it is recognized that AKI sometimes progresses to chronic kidney disease (CKD) and end-stage renal disease (ESRD). Patients with AKI have a higher risk of developing CKD and ESRD, as a systematic review and meta-analysis by Coca et al. [2] has shown. Recent clinical trials have also

Selected paper from a presentation at the 2016 AKI and CRRT UABUCSD O'Brien Center Symposium, San Diego, Calif., USA, February 16,2016 . This symposium was supported in part from a National Institutes of Health grant for the UAB-UCSD O'Brien Center for Acute Kidney Injury Research (P30 DK079337).

\section{KARGER}

(c) 2016 S. Karger AG, Basel

E-Mail karger@karger.com

www.karger.com/nef
Dr. Motoko Yanagita

Department of Nephrology

Kyoto University Graduate School of Medicine

Shogoin-Kawahara-cho 54, Sakyo-ku, Kyoto 606-8507 (Japan)

E-Mail motoy@kuhp.kyoto-u.ac.jp 
demonstrated that the severity and frequency of AKI are related to progression to $\mathrm{CKD}[3,4]$. While clinical epidemiology strongly supports the hypothesis that AKI contributes to progression to CKD or ESRD, the molecular mechanisms involved in the AKI-to-CKD continuum remain unclear. Proximal tubules are mainly damaged in AKI and repaired by their proliferation $[5,6]$. Inadequate repair of proximal tubules might be involved in the progression to CKD. Here, we review the current knowledge of the mechanisms of the AKI-to-CKD continuum, especially the mechanism how injured proximal tubules trigger the progression of AKI-to-CKD.

\section{Fibrosis, Inflammation and Hypoxia: Possible Mechanisms of the AKI-to-CKD Continuum}

One of the major hallmarks of CKD is interstitial fibrosis, characterized by scar-forming myofibroblasts whose origins remain a matter of controversy. We and other groups have shown that resident fibroblasts and pericytes, including erythropoietin (Epo)-producing cells, transdifferentiate into myofibroblasts and are the main contributors to fibrosis [7-9]. Recently, Kramann et al. [10] demonstrated that hedgehog $(\mathrm{Hh})$-responding perivascular Gli1 ${ }^{+}$cells, which constitute a small portion of platelet-derived growth factor- $\beta^{+}$fibroblasts, proliferate after AKI and have the features of progenitors of myofibroblasts.

Infiltration of inflammatory cells is another common feature of CKD. After AKI, various types of inflammatory cells invade the kidney, including neutrophils, monocytes/macrophages, dendritic cells and lymphocytes; these inflammatory cells are also involved in the repair process after AKI $[11,12]$. Macrophages play central roles in kidney injury and repair, and animal models have demonstrated the presence of 2 types of macrophages after AKI. While M1 macrophages migrate to the kidney immediately after the injury and produce proinflamamatory molecules, M2 macrophages emerge in the recovery phase of AKI and secrete profibrotic cytokines. M2 macrophages may help tubular cell proliferation and repair in the resolution of the acute phase of the injury [13], but the sustained infiltration of M2 macrophages leads to fibrosis and contributes to the progression to $\mathrm{CKD}$. Indeed, it is reported that the number of the infiltrated M2 macrophages correlates with the degree of interstitial fibrosis in renal biopsy sample of IgA nephropathy [14].

Loss of peritubular capillaries is another common finding after AKI. Quantitative assessment by fluores- cence microangiography revealed that capillary numbers and areas were decreased after AKI in proportion to the degree of the injury [15]. Loss of peritubular capillaries in AKI causes hypoxia, leading to the progression to CKD. Hypoxia damages tubular epithelial cells, activates inflammatory cells and fibroblasts, and finally leads progresses to CKD [16].

\section{Selective Proximal Tubule Injury Leads to CKD}

\section{Animal Models Showing That Proximal Tubule Injury Is Sufficient to Cause CKD}

The proximal tubule is the main site of injury during $\mathrm{AKI}$, and several groups have hypothesized that injured proximal tubules play important roles in the progression of CKD $[17,18]$. Pathological findings indicate that interstitial fibrosis emerges around injured proximal tubules, lending further support to this hypothesis. For the purpose of testing this hypothesis, however, traditional AKI models caused by ischemic reperfusion injury, toxins and sepsis are not ideal because these injuries affect various types of cells at the same time, so that the models cannot identify the specific cell type that is important in the progression to $\mathrm{CKD}$. To restrict the primary injury to one specific cell population at a time, Cre-LoxP technology in combination with the toxin receptor-mediated cell knockout (TRECK) method has been utilized. Grgic et al. [17] utilized a mouse model in which the simian diphtheria toxin (DT) receptor is expressed on nephron epithelial cells; by adjusting the dose and timing of DT administration, they induced preferential proximal tubule-specific injury, and demonstrated that recurrent proximal tubular injuries drive interstitial fibrosis and glomerulosclerosis. Our groups utilized the TRECK method together with proximal tubule-specific CreERT2 mice [5], in which the administration of tamoxifen activates the inducible form of Cre, and successfully induced selective proximal tubule injuries [18]. By adjusting the doses of tamoxifen and DT, we could induce various types of proximal tubule injuries in this mouse strain. We showed that selective proximal tubule injury causes the transition of fibroblasts to myofibroblasts around the injured proximal tubules, leading to fibrosis and reduced Epo production (fig. 1). We also found that fibrosis was reversible when proximal tubule injury was mild, while recurrent mild proximal tubule injuries caused sustained interstitial fibrosis together with inflammation. We further demonstrated the existence of a threshold level of proximal tubule injury sufficient to induce interstitial fibrosis as 
Fig. 1. Consequences of proximal tubule injury and possible mechanism of the AKIto-CKD continuum. Selective proximal tubule injuries cause several features of CKD: transdifferentiation of fibroblasts to myofibroblasts, distal tubule injury, glomerulosclerosis and atubular glomeruli, and the severity and frequency of proximal tubule injuries determine progression to CKD. When proximal tubule injury is severe, the proximal tubules can become shorter after repair. Protecting the proximal tubules is essential for halting the progression from AKI to CKD.

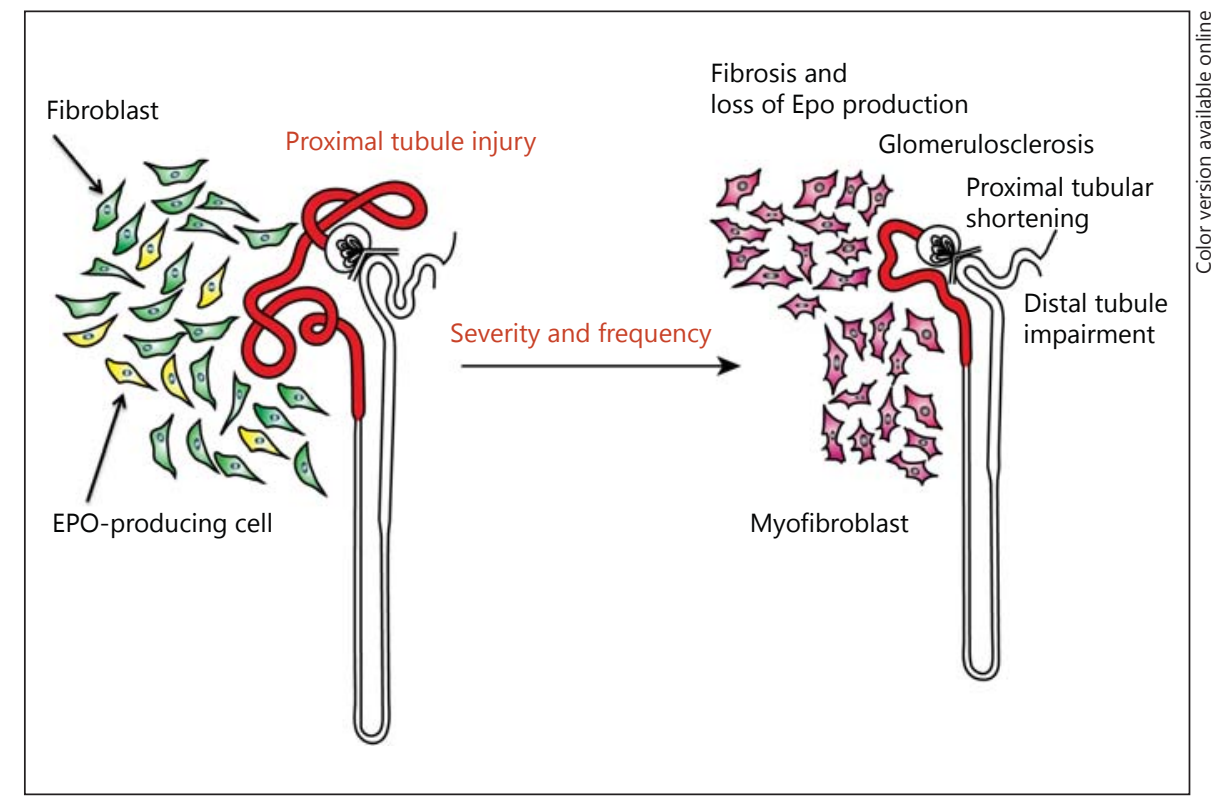

well as distal tubule injury. We also focused on the changes in glomeruli after selective proximal tubule injury, and found that glomeruli remained structurally normal after a single severe proximal tubule injury, but progressed to sclerosis and atubular glomeruli after repeated mild proximal tubule injuries [18]. Taken together, our evidence demonstrates that selective proximal tubule injuries cause several features of CKD, and that the severity and frequency of proximal tubule injuries determine progression to CKD. These findings are in accordance with previous clinical findings showing that the severity and frequency of AKI determine progression to CKD $[3,4]$.

\section{How Does Proximal Tubule Injury Affect Fibroblast}

Activation and Inflammatory Changes?

Kidney injury molecule 1 (KIM-1) expression in the proximal tubules is also involved in the progression to CKD. After injury, KIM-1 is upregulated in the proximal tubules, where it acts as a receptor for phosphatidylserine-mediated phagocytosis. While acute expression of KIM-1 blocks proinflammatory signaling and ameliorates tubule injury [19], prolonged expression of KIM-1 induces sustained inflammation with fibrosis [20]. Furthermore, other signaling pathways in the proximal tubules, such as Hh-Gli, Wnt, Notch and transforming growth factor $\beta$ (TGF- $\beta$ ), have been reported to induce the transdifferentiation of fibroblasts to myofibroblasts [21]. Bechtel et al. [22] demonstrated that TGF- $\beta$ causes epigenetic modification of fibroblasts and sustained fi- brosis. Maarouf et al. [23] recently demonstrated that the activation of Wnt signaling in the proximal tubules directly induces fibrosis without inflammation.

\section{Maladaptive Repair of Proximal Tubules}

Previously, we performed a lineage tracing analysis of proximal tubules and demonstrated that injured proximal tubules repair themselves through their own proliferation [5]. We have also examined the limits of the proximal tubules' capacity for self-repair after severe injury by demonstrating that the proximal tubules are shortened after such repairs (fig. 1). Together with the results of our TRECK analysis, these previous results indicate that severe and frequent proximal tubule injury and inadequate repair are the key determinants of the AKI-to-CKD continuum (fig. 1).

As one of the key cellular mechanisms in the AKI-to$\mathrm{CKD}$ progression, maladaptive repair after $\mathrm{AKI}$ is worth examining. Some researchers have focused on cell cycle arrest in tubular cells after AKI. Yang et al. [24] utilized various AKI models to demonstrate that proximal tubule cells whose cell cycles are arrested at the G2/M checkpoint activate c-jun $\mathrm{NH} 2$-terminal kinase signaling and upregulate the production of profibrotic cytokines, such as TGF $\beta 1$ and connective tissue growth factor, while pharmacological inhibition of G2/M-arrested cells attenuates fibrosis. Recently, cell-cycle-arrest biomarkers such as urine insulin-like growth factor-binding protein 7 and tissue inhibitor of metalloproteinases- 2 have been proven useful for detecting AKI in humans [25]. 


\section{Conclusion}

In summary, several cell populations, factors and molecules are involved in the AKI-to-CKD continuum, a clinically important process. The proximal tubule is the main site of injury in AKI, and injured proximal tubules play important roles in the progression of CKD. Fibrosis after $\mathrm{AKI}$ is, at least in part, a consequence of proximal tubule injury, and therapeutic strategies targeting fibrosis might not be sufficient to halt AKI-to-CKD progression. Inadequate repair of the proximal tubules is considered to be the key cellular mechanism in the AKI-toCKD continuum, and therapeutic strategies to protect the proximal tubules and promote their repair capacity are essential. Modulating molecules in injured proximal tubules will be helpful for halting the progression to CKD. For example, intervention aimed at G2/M arrested cells in proximal tubules might be considered the novel therapeutic strategies. Indeed, histone deacetylase inhib- itors or p53 inhibitors have been shown to ameliorate fibrosis by decreasing G2/M arrested cells in animal models $[24,26]$. Translation of these strategies to humans will help the prevention of AKI-to-CKD continuum.

\section{Acknowledgement}

Present address of K.T.: Department of Nephrology, Otsu RedCross Hospital, Shiga, Japan.

\section{Disclosure Statement}

K.T. has no conflicts of interest to declare. M.Y. is on the advisory board of Astellas and receives research grants from Astellas, Chugai, Daiichi Sankyo, Fujiyakuhin, Kyowa Hakko Kirin, Mitsubishi Tanabe, MSD, Nippon Boehringer Ingelheim, and Torii.

\section{References}

1 Lewington AJ, Cerda J, Mehta RL: Raising awareness of acute kidney injury: a global perspective of a silent killer. Kidney Int 2013;84: 457-467.

-2 Coca SG, Singanamala S, Parikh CR: Chronic kidney disease after acute kidney injury: a systematic review and meta-analysis. Kidney Int 2012;81:442-448.

-3 Ishani A, Nelson D, Clothier B, Schult T, Nugent S, Greer N, Slinin Y, Ensrud KE: The magnitude of acute serum creatinine increase after cardiac surgery and the risk of chronic kidney disease, progression of kidney disease, and death. Arch Intern Med 2011;171:226233.

4 Thakar CV, Christianson A, Himmelfarb J, Leonard AC: Acute kidney injury episodes and chronic kidney disease risk in diabetes mellitus. Clin J Am Soc Nephrol 2011;6:25672572.

5 Endo T, Nakamura J, Sato Y, Asada M, Yamada R, Takase M, Takaori K, Oguchi A, Iguchi T, Higashi AY, Ohbayashi T, Nakamura T, Muso E, Kimura T, Yanagita M: Exploring the origin and limitations of kidney regeneration. J Pathol 2015;236:251-263.

-6 Kusaba T, Lalli M, Kramann R, Kobayashi A, Humphreys BD: Differentiated kidney epithelial cells repair injured proximal tubule. Proc Natl Acad Sci U S A 2014;111:15271532.

7 Asada N, Takase M, Nakamura J, Oguchi A, Asada M, Suzuki N, Yamamura K, Nagoshi N, Shibata S, Rao TN, Fehling HJ, Fukatsu A, Minegishi N, Kita T, Kimura T, Okano H, Yamamoto M, Yanagita M: Dysfunction of fi- broblasts of extrarenal origin underlies renal fibrosis and renal anemia in mice. J Clin Invest 2011;121:3981-3990.

8 Souma T, Yamazaki S, Moriguchi T, Suzuki N, Hirano I, Pan X, Minegishi N, Abe M, Kiyomoto $\mathrm{H}$, Ito S, Yamamoto M: Plasticity of renal erythropoietin-producing cells governs fibrosis. J Am Soc Nephrol 2013;24:15991616.

-9 Duffield JS: Cellular and molecular mechanisms in kidney fibrosis. J Clin Invest 2014; 124:2299-2306

10 Kramann R, Schneider RK, DiRocco DP, Machado F, Fleig S, Bondzie PA, Henderson JM, Ebert BL, Humphreys BD: Perivascular Gli1+ progenitors are key contributors to injury-induced organ fibrosis. Cell Stem Cell 2015;16:51-66.

11 Bonventre JV, Yang L: Cellular pathophysiology of ischemic acute kidney injury. J Clin Invest 2011;121:4210-4221.

12 Meng XM, Nikolic-Paterson DJ, Lan HY: Inflammatory processes in renal fibrosis. Nat Rev Nephrol 2014;10:493-503.

13 Lee S, Huen S, Nishio H, Nishio S, Lee HK, Choi BS, Ruhrberg C, Cantley LG: Distinct macrophage phenotypes contribute to kidney injury and repair.J Am Soc Nephrol 2011;22:317-326.

14 Ikezumi Y, Suzuki T, Karasawa T, Hasegawa H, Yamada T, Imai N, Narita I, Kawachi H, Polkinghorne KR, Nikolic-Paterson DJ, Uchiyama M: Identification of alternatively activated macrophages in new-onset paediatric and adult immunoglobulin A nephropathy: potential role in mesangial matrix expansion. Histopathology 2011;58:198-210.
15 Kramann R, Tanaka M, Humphreys BD: Fluorescence microangiography for quantitative assessment of peritubular capillary changes after AKI in mice. J Am Soc Nephrol 2014;25: 1924-1931.

16 Tanaka S, Tanaka T, Nangaku M: Hypoxia as a key player in the AKI-to-CKD transition. Am J Physiol Renal Physiol 2014;307:F1187-F1195.

17 Grgic I, Campanholle G, Bijol V, Wang C, Sabbisetti VS, Ichimura T, Humphreys BD, Bonventre JV: Targeted proximal tubule injury triggers interstitial fibrosis and glomerulosclerosis. Kidney Int 2012;82:172-183.

18 Takaori K, Nakamura J, Yamamoto S, Nakata $\mathrm{H}$, Sato Y, Takase M, Nameta M, Yamamoto T, Economides AN, Kohno K, Haga H, Sharma $\mathrm{K}$, Yanagita M: Severity and frequency of proximal tubule injury determines renal prognosis. J Am Soc Nephrol 2015:pii:ASN.201506064.

19 Yang L, Brooks CR, Xiao S, Sabbisetti V, Yeung MY, Hsiao LL, Ichimura T, Kuchroo V, Bonventre JV: KIM-1-mediated phagocytosis reduces acute injury to the kidney. J Clin Invest 2015;125:1620-1636.

20 Humphreys BD, Xu F, Sabbisetti V, Grgic I, Movahedi Naini S, Wang N, Chen G, Xiao S, Patel D, Henderson JM, Ichimura T, Mou S, Soeung S, McMahon AP, Kuchroo VK, Bonventre JV: Chronic epithelial kidney injury molecule- 1 expression causes murine kidney fibrosis. J Clin Invest 2013;123:4023-4035.

21 Kramann R, DiRocco DP, Humphreys BD: Understanding the origin, activation and regulation of matrix-producing myofibroblasts for treatment of fibrotic disease. J Pathol 2013; 231:273-289. 
22 Bechtel W, McGoohan S, Zeisberg EM, Muller GA, Kalbacher H, Salant DJ, Muller CA, Kalluri R, Zeisberg M: Methylation determines fibroblast activation and fibrogenesis in the kidney. Nat Med 2010;16:544550.

23 Maarouf $\mathrm{OH}$, Aravamudhan A, Rangarajan D, Kusaba T, Zhang V, Welborn J, Gauvin D, Hou X, Kramann R, Humphreys BD: Paracrine Wntl drives interstitial fibrosis without inflammation by tubulointerstitial cross-talk. J Am Soc Nephrol 2016;27:781790.
4 Yang L, Besschetnova TY, Brooks CR, Shah JV, Bonventre JV: Epithelial cell cycle arrest in G2/M mediates kidney fibrosis after injury. Nat Med 2010;16:535-543, 1p following 143.

25 Kashani K, Al-Khafaji A, Ardiles T, Artigas A, Bagshaw SM, Bell M, Bihorac A, Birkhahn R, Cely CM, Chawla LS, Davison DL, Feldkamp T, Forni LG, Gong MN, Gunnerson KJ, Haase M, Hackett J, Honore PM, Hoste EA, JoannesBoyau O, Joannidis M, Kim P, Koyner JL, Laskowitz DT, Lissauer ME, Marx G, McCullough PA, Mullaney S, Ostermann M,
Rimmele T, Shapiro NI, Shaw AD, Shi J, Sprague AM, Vincent JL, Vinsonneau C, Wagner L, Walker MG, Wilkerson RG, Zacharowski K, Kellum JA: Discovery and validation of cell cycle arrest biomarkers in human acute kidney injury. Crit Care 2013;17:R25.

6 Cianciolo Cosentino C, Skrypnyk NI, Brilli LL, Chiba T, Novitskaya T, Woods C, West J, Korotchenko VN, McDermott L, Day BW, Davidson AJ, Harris RC, de Caestecker MP, Hukriede NA: Histone deacetylase inhibitor enhances recovery after AKI. J Am Soc Nephrol 2013;24:943-953. 